\title{
AC 2010-986: HYBRID COURSE FORMAT FOR PROJECTS IN ROBOTICS
}

\section{Hakan Gurocak, Washington State University, Vancouver}

Hakan Gurocak is Director of School of Engineering and Computer Science and Associate Professor of Mechanical Engineering at Washington State University Vancouver. His research interests are robotics, automation, fuzzy logic, technology assisted distance delivery of laboratory courses and haptic interfaces for virtual reality. Dr. Gurocak is an ABET Program Evaluator for mechanical engineering. 


\title{
HYBRID COURSE FORMAT FOR PROJECTS IN ROBOTICS
}

\begin{abstract}
In this paper a hybrid course format is presented. It is an alternative way to introduce hands-on experience into an otherwise lecture-only format robotics course. The course runs as a lecture course for the first half of the semester. In the second half, it turns into a "studio" setting where the students meet during the regular weekly lecture hours in the robotics lab instead. Details of the project assignment, hardware, software, grading and course assessment are explained. Three sample projects are provided.
\end{abstract}

\section{Introduction}

Robotics courses are commonly found in many universities. They include coverage of introductory background in industrial robotics and often utilize some form of robot motion simulation using software such as MATLAB.

Robotics integrates computer programming, electronics and mechanical design into a final product or system. As such, it provides an exciting platform for hands-on learning ${ }^{1-7}$. However, the lecture-only format of the typical robotics courses cannot take full advantage of this. It is possible to change the format into a lecture-and-lab format, as is the case at many universities. But often there is no room in the curriculum for additional credits or additional resources, such as teaching assistants for the lab, are not available to accomplish this change.

This paper presents a hybrid course format as an alternative way to introduce hands-on experience into an otherwise lecture-only format robotics course. The course runs as a lecture course for the first half of the semester. In the second half, it turns into a "studio" setting where the students still meet during the regular weekly lecture hours but in the robotics lab instead. They work on projects in teams and interact with the instructor, teaching assistant and other students. This format provides an attractive alternative to the common lecture-and-lab format since it reduces the number of hours students have to spend on campus by incorporating the lab into the regular lecture hours. Students appreciate this since most of them work to put themselves through school. The hybrid approach is different than a project assignment in a regular course since the students work on the projects with the guidance of the instructor during the regular lecture hours.

After a brief review of the course content, the paper discusses the details of the project assignment. Three example projects are provided. Next assessment of the project and the course outcomes are presented. Finally, results of course offerings in this format for four years are presented.

\section{Hybrid course structure}

The Mech 468 "Robotics" course is a 3 semester credit lecture-only senior level elective in our mechanical engineering program. It can be taken either as a free elective or as the last course of a three-course mechatronics option track in our curriculum. 
The course runs as a lecture course for the first half of the semester. In the second half, it turns into a "studio" setting where the students still meet during the regular weekly lecture hours in the robotics lab.

The first half of the course aims to cover introductory concepts found in typical industrial robotics courses (Table 1). Primarily spatial description of position and orientation in 3D space, transform matrices, manipulator kinematics, position and velocity analysis, manipulator Jacobian and static force analysis are covered. The main goals are to enable the students to understand the mathematical methods behind spatial representation of position and orientation and their application to study motion of industrial robots in 3D space.

Table 1

Robotics Course Content

\begin{tabular}{|c|c|}
\hline Week & Topics covered \\
\hline 1 & $\begin{array}{l}\frac{\text { Sub-systems and components of a robot }}{\text { Mechanical, electrical, process, control, sensor and planning sub-systems; robot arms; }} \\
\text { robotic actuators; transmission elements. } \\
\frac{\text { Spatial Descriptions and Transformations }}{\text { Position, Orientation and frames; Mappings; Transform operator. }}\end{array}$ \\
\hline 2 & $\frac{\text { Spatial Desc. and Trans. }(\text { cont'd) }}{\text { Rotation operators; Transform equations; Absolute and Relative transformations. }}$ \\
\hline 3 & $\frac{\text { Spatial Desc. and Trans. }(\text { cont'd) }}{\text { Absolute and Relative transformations. }}$ \\
\hline 4 & $\begin{array}{l}\text { Manipulator Kinematics } \\
\text { Link description; Denavit-Hartenberg convention; Manipulator kinematics; Forward } \\
\text { kinematics equation. }\end{array}$ \\
\hline 5 & Manipulator Kinematics $\left(\right.$ cont $\left.^{\prime} d\right)$ \\
\hline 6 & Manipulator Kinematics (cont'd) \\
\hline 7 & $\begin{array}{l}\text { Jacobian: Velocity Analysis } \\
\text { Time-varying position and orientation; Velocity propagation from link to link; Jacobian } \\
\text { computation. }\end{array}$ \\
\hline 8 & $\frac{\text { Jacobian: Vel. and Static Forces }}{\text { Static forces in the manipulators; Jacobian in the force domain. }}$ \\
\hline
\end{tabular}

After the study of the Jacobian (week 8 in Table 1), a typical robotics course would continue into manipulator dynamics by taking the mathematical methods one step further. Then, manipulator control algorithms would be introduced. The equations for manipulator dynamics are very complex; therefore they cannot be computed by hand. Furthermore, the control theory associated with robots is fairly complex due to the multi-degree-of-freedom mechanism and the nonlinearities. After teaching robotics for many years, it has been the author's experience that the majority of the students cannot grasp these "advanced" concepts and lose interest. Based on 
this experience and the need to introduce hands-on content a compromise has been made by dropping dynamics and control coverage from the course and replacing them with the "studio" approach for a hands-on project.

The project involves design and building of a robotic assembly cell that integrates an industrial robot with peripheral hardware and a vision system through control software. Student teams design the peripheral hardware and the control software to complete the robotic cell.

The studio portion of the class runs through the $2^{\text {nd }}$ half of the semester. The class still meets only during the regular lecture hours (50 minutes three times a week). But instead of meeting in the regular classroom, we meet in the lab. Student teams of three or four members are formed.

The studio portion starts with introduction to the programming environment (Table 2). Any programming language can be used for this purpose but we chose Microsoft Visual Basic (VB) due to the quick learning curve and its flexibility to develop professional looking Windows programs very quickly. Most students do not know anything about VB but they can pick it up in a short period of time. In the first week of the studio format, the instructor goes over a tutorial with the students as they work on the computers, following the instructions. In the second week, we cover the VB programming details related to the hardware such as the data acquisition card, the vision system and the communication with the robot. Code segments for each piece of hardware are provided to the students. They experiment with the VB code, such as changing exposure time on the camera from the VB program, and observe the results with the hardware. In the rest of the semester, students work on their projects in teams with an end goal of a robotics open house where they demonstrate their projects to guests.

Table 2

Studio Portion of the Robotics Course

\begin{tabular}{|c|c|}
\hline Week & Topics covered \\
\hline 9 & $\frac{\text { Programming with Visual Basic }}{\text { Basic concepts of event-driven programming, user interface design, syntax. }}$ \\
\hline 10 & $\frac{\text { VB programming for hardware interaction }}{\text { Experimentation with code segments to interact with hardware from the VB program. }}$ \\
\hline 11 & $\underline{\text { Robotics project }}$ \\
\hline 12 & $\underline{\text { Robotics project }}$ \\
\hline 13 & $\underline{\text { Robotics project }}$ \\
\hline 14 & $\underline{\text { Robotics project }}$ \\
\hline 15 & $\underline{\text { Robotics project }}$ \\
\hline 16 & $\underline{\text { Robotics Open House }}$ \\
\hline
\end{tabular}




\section{Project assignment}

The challenge with finding a good project is that it should require minimal fabrication and time outside the class since the goal of the hybrid format is to provide hands-on experience without demanding extra class or lab time beyond the regular lecture hours. In addition, if possible, the project should involve some basic electronics, programming (VB) and system integration.

In designing the prototype robotics cell, the students are expected to follow the steps of a typical design process. The project assignment contains the form shown in Figure 1. In this form, the beginning and end dates of the project are set by the instructor. The intermediate deadlines and the deliverables are set by the design team. This flexibility gives the teams an opportunity to work around their own schedules. After they receive the project assignment (on March 23, 2009 in this example), they have one week to get together as a team, discuss the project and develop a project plan including milestones, deadlines and deliverables. Once the form is submitted, we track each team separately and hold them responsible for their deadlines. Every time they don't meet a deadline, 3 points are deducted from their total project score.

\begin{tabular}{|c|c|c|}
\hline Design process components & Description & Deadline \\
\hline $\begin{array}{l}\text { Project plan with Gantt chart } \\
\text { attached }\end{array}$ & $\begin{array}{l}\text { Project timeline, including milestones and } \\
\text { deliverables. }\end{array}$ & March 30, 2009 \\
\hline Conceptual designs & $\begin{array}{l}\text { Conceptual design can include hardware and } \\
\text { software concepts (solutions) you generate for the } \\
\text { design problem. Minimum } 2 \text { concepts required. }\end{array}$ & $\begin{array}{l}\text { Use attached form to } \\
\text { specify deadline }\end{array}$ \\
\hline $\begin{array}{l}\text { Concept evaluation and detailed } \\
\text { design }\end{array}$ & $\begin{array}{l}\text { Evaluate the conceptual designs and select one to } \\
\text { use. Design the details of the hardware and the } \\
\text { software algorithm. }\end{array}$ & $\begin{array}{l}\text { Use attached form to } \\
\text { specify deadline }\end{array}$ \\
\hline Build a prototype & Build a prototype, including hardware and software. & $\begin{array}{l}\text { Use attached form to } \\
\text { specify deadline }\end{array}$ \\
\hline Testing & $\begin{array}{l}\text { Test all functions of the prototype, finalize the } \\
\text { product. }\end{array}$ & $\begin{array}{l}\text { Use attached form to } \\
\text { specify deadline }\end{array}$ \\
\hline Project presentation & Give a demo. & April 27, 2009 \\
\hline
\end{tabular}

Figure 1. Form used in the project assignment. Teams set their own deadlines and deliverables following the steps of design process.

Table 3 shows the project grade breakdown. The codes in the first column are related to the ABET assessment which is explained later in Section V. 
Table 3

Project Grading

\begin{tabular}{|c|c|c|}
\hline Course outcome & $\begin{array}{l}\text { Project Grade } \\
\text { Criteria }\end{array}$ & Points \\
\hline $\begin{array}{l}\text { C-3, C-4, K-2, K-3 } \\
\text { C-4, K-2 } \\
\text { C-4, K-2 } \\
\text { C-4, K-3 } \\
\text { C-4, K-2 } \\
\text { C-4, K-3 } \\
\text { C-2 } \\
\text { D-1, D-2, D-3 }\end{array}$ & $\begin{array}{l}\text { Functioning prototype } \\
\text { Clamp design } \\
\text { Electronic circuit construction } \\
\text { Operator interface } \\
\text { Compliance for cap motion } \\
\text { Software design } \\
\text { Met deadlines } \\
\text { Team contributions }\end{array}$ & $\begin{array}{r}38 \\
10 \\
10 \\
5 \\
5 \\
10 \\
12 \\
10 \\
100\end{array}$ \\
\hline
\end{tabular}

At the end of the project, each student is asked to submit an evaluation form for each of the team members on his/her team (Figure 2). The form asks for scores and comments. The instructor then determines the individual scores for the "team contributions" item on the project grade for each student. This determination is based on the observations of individual student work throughout the project and the scores given to each student by their team members.

\begin{tabular}{|l|l|}
\hline Criteria & Score (1 to 5) \\
\hline $\begin{array}{l}\text { This team member contributed to the team work at the } \\
\text { level expected by the team }\end{array}$ & \\
\hline $\begin{array}{l}\text { This team member contributed to the conceptual design } \\
\text { ideas at the level expected by the team }\end{array}$ & \\
\hline $\begin{array}{l}\text { This team member worked effectively with others on } \\
\text { the team }\end{array}$ & \\
\hline
\end{tabular}

Figure 2. Form used for team member evaluation.

\section{Sample projects}

\section{IV.1. Robotic cell for bottle processing}

In this project the goal is to design a robotic cell that can pick up a bottle and pour a drink into a cup.

\footnotetext{
The system will work as follows:
}

1. A bottle and a cup will be placed at arbitrary locations in the workspace of the robot by a user.

2. Vision system will find the bottle and the cup. It will then direct the robot to pick up the bottle and put it into an automated clamp.

3. The clamp will hold the bottle while the robot unscrews the cap.

4. The robot will pick up the bottle and move it over to the cup location to pour the drink into the cup.

5. The robot will grasp the full cup, lift it up and hand it to the user. The bottle will need to be returned to the original pick up position to end the cycle.

6. The cycle will be repeated if a new bottle (with cap on) and a cup are provided by the user.

7. An operator interface on the PC will provide real-time status information to the user. 


\section{Design specifications:}

1) The clamp must be constructed from lightweight materials (wood and plastic construction. No metal construction). However, some metal parts can be used.

2) The construction must be high quality for future demonstrations.

3) The system should be modular so that it can be set up easily.

4) The operator interface must show the current state of the machine at any given time.

5) When you want to carry the bottle or pour drink from it, the robot needs to hold it from the side. It is not allowed to grasp it simply from the cap.

6) The bottle needs to be filled with one full cup of drink before starting the task.

7) You cannot change the location of camera and/or robot

8) When the cap is unscrewed by the robot, the cap will advance along its axis towards the base of the hand in between the fingers of the robot. Since the robot will be holding the cap firmly to unscrew it, there is no compliance. As a result, quite a bit of stress is put on the joints of the robot. Your design needs to take this into consideration by incorporating some sort of compliance to allow the robot to unscrew the cap without putting any stress on its joints.

This project requires fabrication of a clamp controlled by one DC motor. When the motor is rotated in the forward direction, the clamp closes to hold the bottle. When the motor is reversed, the clamp opens. Switches are used at each end of the clamp motion to determine clamp position. Students design and build the clamp using plastic, cardboard, wood, etc. The motor control and the switch debouncing circuit diagrams are provided in the assignment (Figure 3). With the help of the instructor and the teaching assistant, each student team builds these circuits. They gain basic understanding of interfacing a motor to a PC and electronic circuit construction.

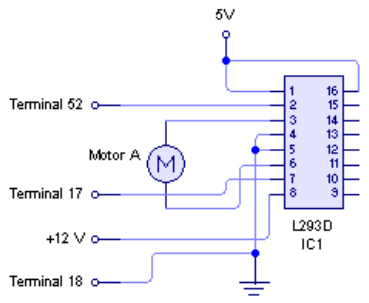

Motor Control Circuit

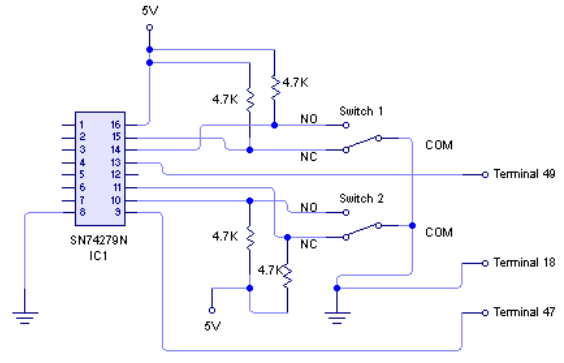

Switch Debouncing Circuit

Figure 3. Motor control and switch debouncing circuits for automatic clamp.

System hardware - The clamp is interfaced to the PC through a data acquisition (DAQ) card by National Instruments (PCI-MIO-16E-4). The vision system consists of a DVT camera that can process images, find object coordinates and send them to the PC. The cell is built around a Mitsubishi RV-1A 6 axis industrial robot. The control software developed in VB by the students runs on the $\mathrm{PC}$ and communicates with the robot and the vision system over the network as it controls the clamp through the DAQ card.

The course has a lab fee collected from the students during registration. The cost of project materials is covered from these funds. 


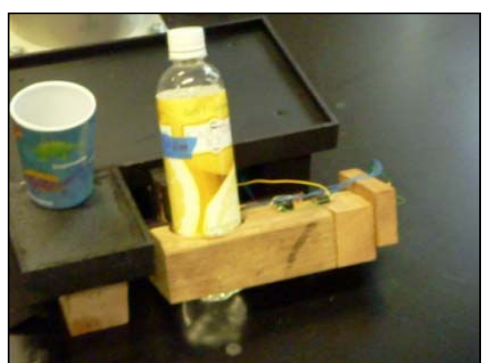

Automatic clamp design

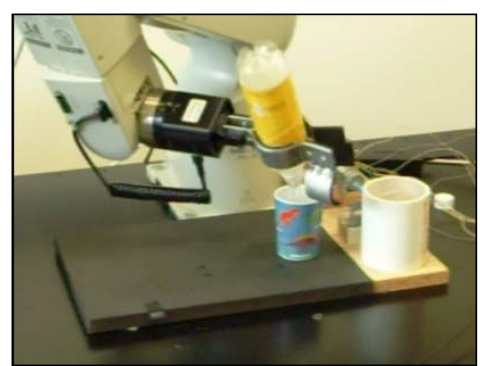

Robot pouring the drink into the cup

Figure 4. Sample student projects (Robotic cell for bottle processing).

\section{IV.2. Robotic cell for packaging golf balls}

In this project the goal is to design a robotic cell that can package golf balls into boxes.

The machine will work as follows:

1. Multiple golf balls will be fed to the cell from a feeder.

2. Vision system will find the balls and direct the robot to pick them up.

3. Robot will retrieve an empty box from a box stack and pack it with golf balls ( 12 balls in each box).

4. The packed box will be added to the stack of finished products (boxes with golf balls).

5. The cycle will be repeated by feeding the next batch of golf balls to the cell.

6. An operator interface on the PC will provide status information to the user.

\section{Design specifications:}

1) The cell must be constructed from lightweight materials (wood and plastic construction. No metal construction). However, some metal parts can be used.

2) The construction must be high quality for future demonstrations.

3) The system should be modular so that it can be easily set up.

4) The operator interface must show the current state of the machine at any given time.

5) Budget constraint: The lowest cost design will receive 5 bonus points.

6) Performance constraint: The highest speed design in packing and stacking 2 boxes will receive 5 bonus points.

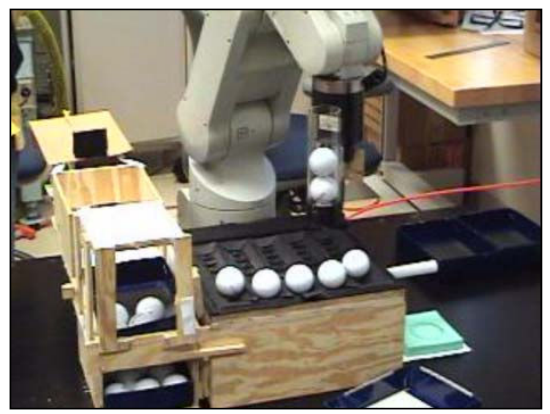

Innovative end-effector design to pick up multiple balls at once

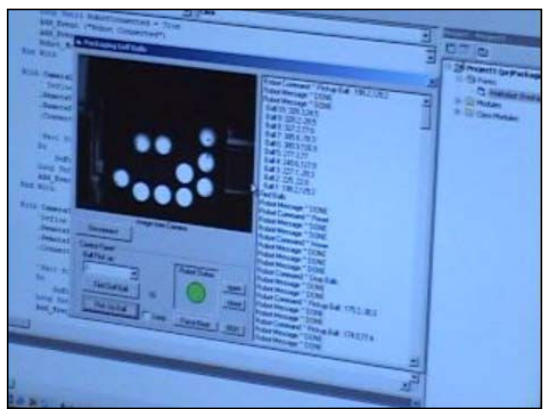

User interface and control program by a student team

Figure 5. Sample student projects (Robotic cell for packaging golf balls). 


\section{IV.3. Robo-Golfer}

In many manufacturing applications of an industrial robot, the application requires part handling with an integrated vision system. In this configuration, the parts can be fed to the robot at random positions and orientations. The vision system that measures part locations can inform the robot about where to find the next part to be handled and its orientation. This project aims to teach the general ideas behind robotic part handling with an integrated vision system by developing a robotic system cell that manipulates golf balls.

Given a tray full of golf balls, the robot will:

1. Pick up all balls in the tray and put them on tees placed along the front edge of the tray

2. Pick up a miniature golf club

3. Knock each ball down into the tray with the golf club (Note: in each run the golf balls will end up at random locations in the tray)

4. Put the club back on the tray

5. Repeat steps 1 through 3 until stopped by the user

\section{Design specifications:}

1. The tray must be constructed from lightweight materials (wood and plastic construction. No metal construction).

2. The construction must be high quality for future demonstrations.

3. The system should be modular so that it can be easily set up.

4. Finger extensions must be built for the robot to pick up the golf balls.

5. The operator interface must show the current state of the machine at any given time.

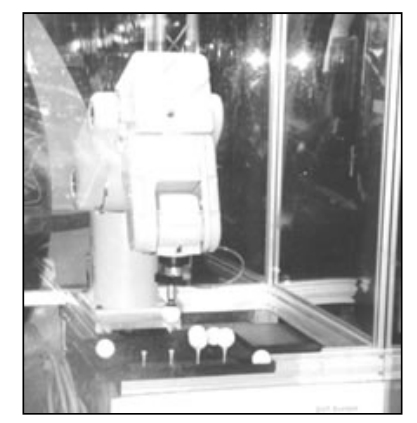

Sample Robo-Golfer with some of the balls on the tees

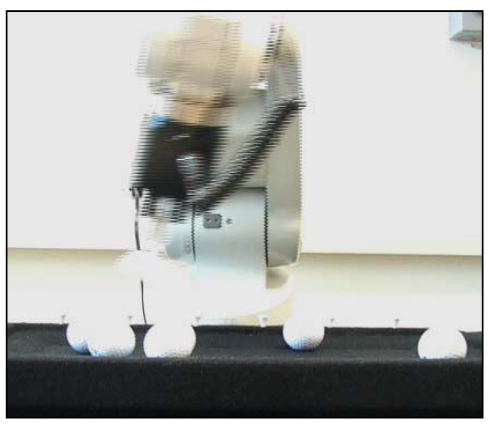

Robo-Golfer in motion

Figure 6. Sample student projects (Robo-Golfer).

\section{Assessment}

Course outcomes are given in Figure 7. As it can be seen from the first column in Table 3, the project grading is closely tied to the course outcomes. The course outcomes, in turn, are tied to the program outcomes for ABET assessment. 


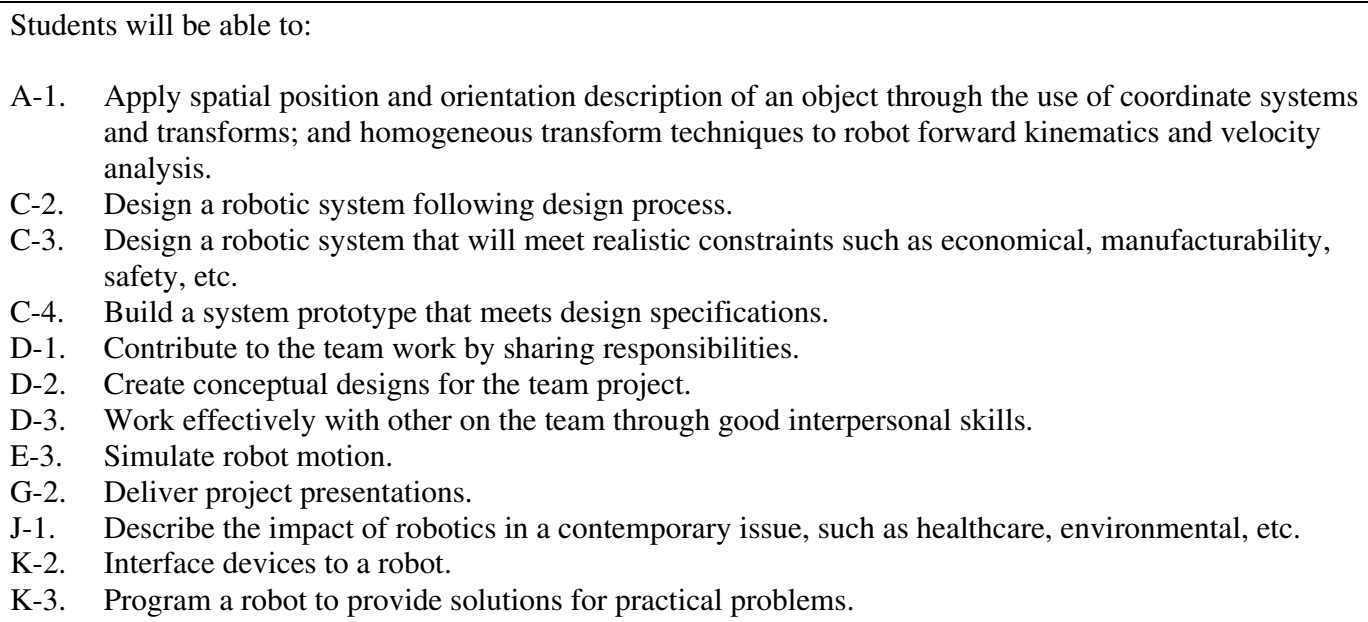

A-1. Apply spatial position and orientation description of an object through the use of coordinate systems and transforms; and homogeneous transform techniques to robot forward kinematics and velocity analysis.

C-2. Design a robotic system following design process.

C-3. Design a robotic system that will meet realistic constraints such as economical, manufacturability, safety, etc.

C-4. Build a system prototype that meets design specifications.

D-1. Contribute to the team work by sharing responsibilities.

D-2. Create conceptual designs for the team project.

D-3. Work effectively with other on the team through good interpersonal skills.

E-3. Simulate robot motion.

G-2. Deliver project presentations.

J-1. Describe the impact of robotics in a contemporary issue, such as healthcare, environmental, etc.

$\mathrm{K}-2$. Interface devices to a robot.

K-3. Program a robot to provide solutions for practical problems.

Figure 7. Course outcomes.

In each course, we assess the course outcomes using direct and indirect assessment tools. Course outcomes are measured throughout the semester by assigning problems targeting these skills on homework and exams. The project contributes significantly to the achievement of most of the course outcomes. After analyzing the data, each student is assigned a score on the scale of 1 to 5 (highest), indicating their achievement of each course outcome. The data coming from each course are then combined to analyze and evaluate the level of achievement of each program outcome. If any program outcomes are not met at the targeted level, then actions are taken to improve the program ${ }^{8-12}$. Table 4 shows the assessment scores for the course outcomes (5highest).

The assessment results show that all course outcomes except for the K-3 outcome are achieved at the level of 4 or above which is very good. The K-3 outcome targets programming. In general, the mechanical engineering students do not feel comfortable with programming. Therefore, this result is somewhat expected.

Table 4

Assessment Scores for Course Outcomes (5-highest)

\begin{tabular}{|c|c|c|c|c|c|c|}
\hline \multicolumn{7}{|c|}{ Mech 468} \\
\hline \multirow{2}{*}{$\begin{array}{l}\text { Course } \\
\text { Outcome }\end{array}$} & Average & \multicolumn{5}{|c|}{ Distribution (\%) } \\
\hline & (Ave.) & 5 & 4 & 3 & 2 & 1 \\
\hline $\mathrm{A}-1$ & 4.4 & $50 \%$ & $36 \%$ & $14 \%$ & $0 \%$ & $0 \%$ \\
\hline $\mathrm{C}-2$ & 4.3 & $29 \%$ & $71 \%$ & $0 \%$ & $0 \%$ & $0 \%$ \\
\hline $\mathrm{C}-3$ & 4.1 & $57 \%$ & $0 \%$ & $43 \%$ & $0 \%$ & $0 \%$ \\
\hline C-4 & 4.6 & $57 \%$ & $43 \%$ & $0 \%$ & $0 \%$ & $0 \%$ \\
\hline D-1 & 4.6 & $79 \%$ & $7 \%$ & $14 \%$ & $0 \%$ & $0 \%$ \\
\hline D-2 & 4.9 & $86 \%$ & $14 \%$ & $0 \%$ & $0 \%$ & $0 \%$ \\
\hline D-3 & 4.6 & $71 \%$ & $21 \%$ & $7 \%$ & $0 \%$ & $0 \%$ \\
\hline E-3 & 4.2 & $40 \%$ & $50 \%$ & $0 \%$ & $10 \%$ & $0 \%$ \\
\hline G-2 & 4.0 & $14 \%$ & $79 \%$ & $0 \%$ & $7 \%$ & $0 \%$ \\
\hline $\mathrm{J}-1$ & 4.1 & $46 \%$ & $23 \%$ & $23 \%$ & $8 \%$ & $0 \%$ \\
\hline $\mathrm{K}-2$ & 5.0 & $100 \%$ & $0 \%$ & $0 \%$ & $0 \%$ & $0 \%$ \\
\hline K-3 & 3.4 & $21 \%$ & $0 \%$ & $79 \%$ & $0 \%$ & $0 \%$ \\
\hline
\end{tabular}




\section{Conclusions}

In this paper a hybrid course format has been presented. It is an alternative to introduce handson experience into an otherwise lecture-only format robotics course. The course runs as a lecture course for the first half of the semester. In the second half, it turns into a "studio" setting where the students still meet during the regular weekly lecture hours in the robotics lab. Since it incorporates the lab into the regular lecture hours, it reduces the number of hours students have to spend on campus. Students appreciate this since most of them work to put themselves through school. In programs where it is not possible to expand the curriculum by adding a lab course or where the resources, such as teaching assistants, are unavailable, the hybrid format can be a viable option.

The studio approach significantly improved the student confidence and success in the course. They were very interested in gaining hands-on experience in the interdisciplinary subjects of robotics involving programming, electronics and mechanical design. They were also very excited about the demonstration of their completed projects. This was a significant improvement over our experience in the past offerings of the course in lecture-only format. Over the past four years there were 14 teams that worked on these projects. Only 2 teams could not complete their projects successfully, although they were very close.

In many institutions, including ours, typical lab course sessions involve following written instructions while working with lab equipment. The hybrid format is different in that it requires integration of knowledge, designing and building a prototype while keeping the weekly time commitment the same as a lecture-only course. The hybrid approach can also be adapted in other lecture-only courses.

\section{References}

1. Berry, C, Boutell, M, Chenoweth, S. and Fisher, D., "MERI: Multidisciplinary educational robotics initiative," Proceedings of ASEE Annual Conference, Austin, TX, June 2009.

2. Edinbarough, I., Martinez, J., "Web-based control for mechatronics laboratory experiments," Proceedings of ASEE Annual Conference, Austin, TX, June 2009.

3. McGrath, E., Lowes, S., Lin, P. and Sayres, J., "Analysis of middle- and high-school students' learning of science, mathematics and engineering concepts through Lego underwater robotics design challenge," Proceedings of ASEE Annual Conference, Austin, TX, June 2009.

4. Chang, D., Hanlon, P., Ingold, K. and Rabb, R., "Educating generation in robotics," Proceedings of ASEE Annual Conference, Austin, TX, June 2009.

5. Stienecker, A, "Applied industrial robotics: a paradigm shift," Proceedings of ASEE Annual Conference, Pittsburgh, PA, June 2008

6. Reed, A., et.al., "Utilizing robotics to facilitate project-based learning: a student perspective," Proceedings of ASEE Annual Conference, Pittsburgh, PA, June 2008.

7. Gallagher, J., Drushel, R. and Bolick, D., "Increasing accessibility to a first-year engineering course in mobile autonomous robotics," Proceedings of ASEE Annual Conference, Portland, OR, June 2005.

8. Gurocak, H.B., "Planning and implementing an assessment process with performance criteria for ABET accreditation," International Journal of Engineering Education, vol. 25, no. 6, pp. 1236-1248, 2009.

9. Gurocak, H.B., Chen, X. Kim, D. and Jokar, A., "Assessment of program outcomes for ABET accreditation," Proceedings of ASEE Annual Conference, Austin, TX, June 2009. Honorable mention (Third place for best paper award, Mechanical Engineering Division).

10. Gurocak, H.B., "Direct measures for course outcomes assessment for ABET accreditation," Proceedings of ASEE Annual Conference, Pittsburgh, PA, June 2008.

11. Gurocak, H.B., "Automation course with direct measures for ABET outcomes assessment," Proceedings of 2007 ASME International Mechanical Engineering Congress and Exposition, November, Seattle, WA.

12. Gurocak, H.B., "Multilevel program assessment for ABET accreditation in the United States," Proceedings of ASEE Global Colloquium, Istanbul, Turkey, October 2007. 